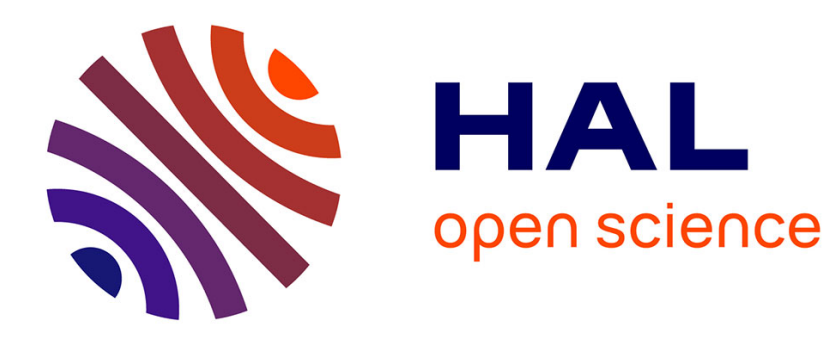

\title{
Statistical evidence of tax fraud on the carbon allowances market
}

Marius-Cristian Frunza, Dominique Guegan, Antonin Lassoudière

\section{To cite this version:}

Marius-Cristian Frunza, Dominique Guegan, Antonin Lassoudière. Statistical evidence of tax fraud on the carbon allowances market. 2010. halshs-00523458

\section{HAL Id: halshs-00523458 \\ https://shs.hal.science/halshs-00523458}

Submitted on 5 Oct 2010

HAL is a multi-disciplinary open access archive for the deposit and dissemination of scientific research documents, whether they are published or not. The documents may come from teaching and research institutions in France or abroad, or from public or private research centers.
L'archive ouverte pluridisciplinaire HAL, est destinée au dépôt et à la diffusion de documents scientifiques de niveau recherche, publiés ou non, émanant des établissements d'enseignement et de recherche français ou étrangers, des laboratoires publics ou privés. 


\section{Documents de Travail du Centre d'Economie de la Sorbonne}

U

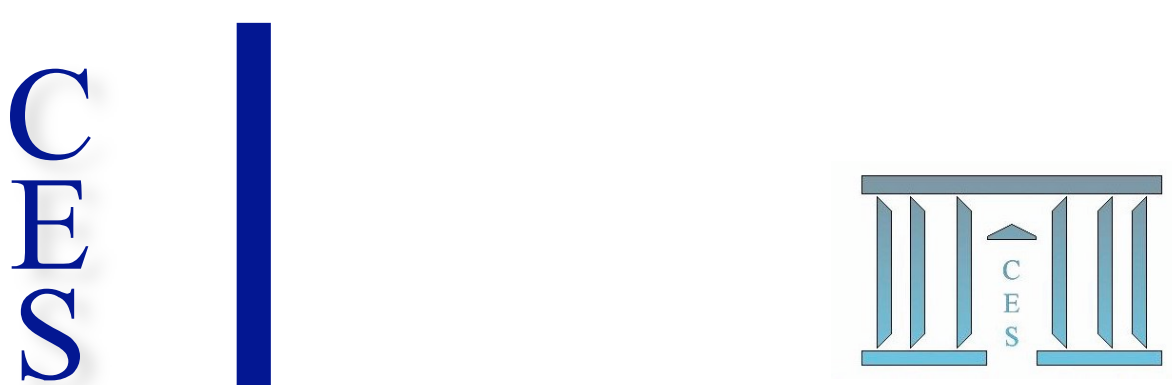

Statistical evidence of tax fraud on the carbon

allowances market

Marius-Cristian FrunZA, Dominique GuEgan, Antonin LAssoudieRE

2010.69

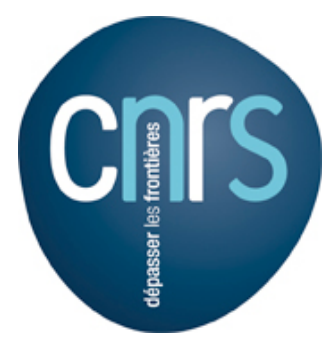

Maison des Sciences Économiques, 106-112 boulevard de L'Hôpital, 75647 Paris Cedex 13 


\title{
STATISTICAL EVIDENCE OF TAX FRAUD ON THE CARBON ALLOWANCES MARKET
}

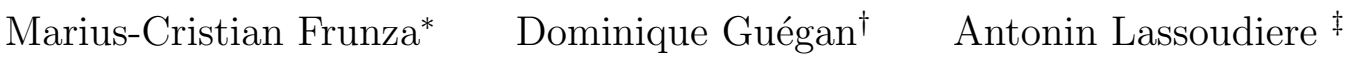

June 27, 2010

\begin{abstract}
The aim of this paper is to show evidence and to quantify with forensic econometric methods the impact of the Value Added Tax fraud on European carbon allowances markets. This fraud mainly occurred at the beginning of between the end of 2008 and the beginning of 2009. In this paper we explore the financial mechanisms of the fraud and the impact on the market behavior as well as the reflexion on its econometric features.

In a previous work, we showed that the European carbon market is strongly influenced by fundamentals factors as oil, energy, gas, coal and equity prices. Therefore, we calibrated Arbitrage Pricing Theory-like models and showed that they have a good forecast capacity. Those models enabled us to quantify the impact of each factor on the market. In this study, we focused more precisely on the benchmark contract for European carbon emissions prices over 2008 and 2009. We observed that during the first semester of 2009, there is a significant drop in our model performances and robustness and that the part of market volatility explained by fundamentals reduced. Therefore, we identified the period where the market was driven by VAT fraud movements and we were able to measure the value of this fraud. Soon after governments passed a law that cut the possibility of fraud occurrence the performance of the model improved rapidly.
\end{abstract}

We estimate the impact of the VAT extortion on the carbon market at 1.3 billion euros.

Keywords: Carbon, EUA, Energy, Arbitrage Pricing Theory, Switching regimes, Hidden Markov Chain Model, Forecast.

\section{Introduction}

In the torments generated by the last economic fall new sources of illegitimate yields have risen across the financial industry. The perpetual competition among investment professionals for supplying with more attractive returns led in a lot of cases to cross not only the efficient

\footnotetext{
*Sagacarbon, a subsidiary of Caisse des Dépôts, marius.frunza@gmail.com

${ }^{\dagger}$ PSE, Centre d'Economie de la Sorbonne, University Paris 1 Panthéon-Sorbonne and Sagacarbon, MSE, 106 bd de l'Hôpital, 75013 Paris, France. Email: dguegan@univ-paris1.fr.. Tel: +33140078298.

‡Sagacarbon, a subsidiary of Caisse des Dépôts, antonin.lassoudiere@gmail.com
} 
but also the legal frontier. As a result the number of investment institutions and markets allegedly linked to fraud schemes multiplied over the last three years. From the historical loss of Jerome Kerviel reputed trader with Societe Generale to the massive havoc provoked by the Madoff system the financial industry have passed through a challenging period in term of public image. If the new acts proposed by different investment authorities have enforced the role of the control function inside the financial institutions, less attention is payed to statistical analysis of market fundamentals or trading styles that could show proofs of price manipulations or frauds. Econometric research as a forensic tool is a relatively new field and less literature is available on this topic. If "pump and dump" schemes could be tracked by classic investigatory means, recent cases of market fraud show the necessity of a deeper statistical analysis of mechanisms and consequences following the financial white collar crime.

The aim of this paper is first to extend the actual literature on carbon markets and on the use of statistics as a forensic tool. Second we focus on a financial fraud that allegedly took place on a new market, the carbon emission allowances exchange. The fraud consisted mainly in cashing out the Value Added Taxes proceedings from allowances sales instead of returning it to governments.

In the first part of the work we describe the mechanism of the fraud scheme and we give few arguments that could explain the changes in market metrics. In the second part we explain our statistical methodology that brings relevant proofs for the fact that the VAT extortion scheme was not an isolated phenomena and had a serious influence on prices dynamics. In the third part we discuss the results. The fourth part concludes.

\section{The carbon VAT scheme}

The EU emission trading system (ETS) raised in 2005 and is now by far the largest multinational scheme in the world (73\% of the value of the global carbon market in 2008). The scheme is a "cap and trade" system whose objective is to cut greenhouse gas emissions by allocating emission allowances (allocated for free or auctioned) which can then be transferred between operators. Phase 3 of the ETS (2013-2020) will incorporate a yearly decrease of the cap of $1.74 \%$ per year, arriving at a reduction of $21 \%$ below the 2005 emissions. Transfers of allowances between taxable persons are considered as a supply of service and were taxable at the place where the recipient is established.

During the summer of 2009, a number of suspected cases of fraud were detected in several EU Member States and have led different EU governments to take swift action by including the greenhouse gas emission allowances in the list of supplies to which a (domestic) reverse charge system could be applied. As a consequence in June 2009 the governments of France and The Netherlands have removed the VAT from carbon permits. 
The so-called carousel Value Added Tax (VAT) fraud or missing trader fraud involving carbon emissions allowances, or carbon credits is summarized in Figure 1.

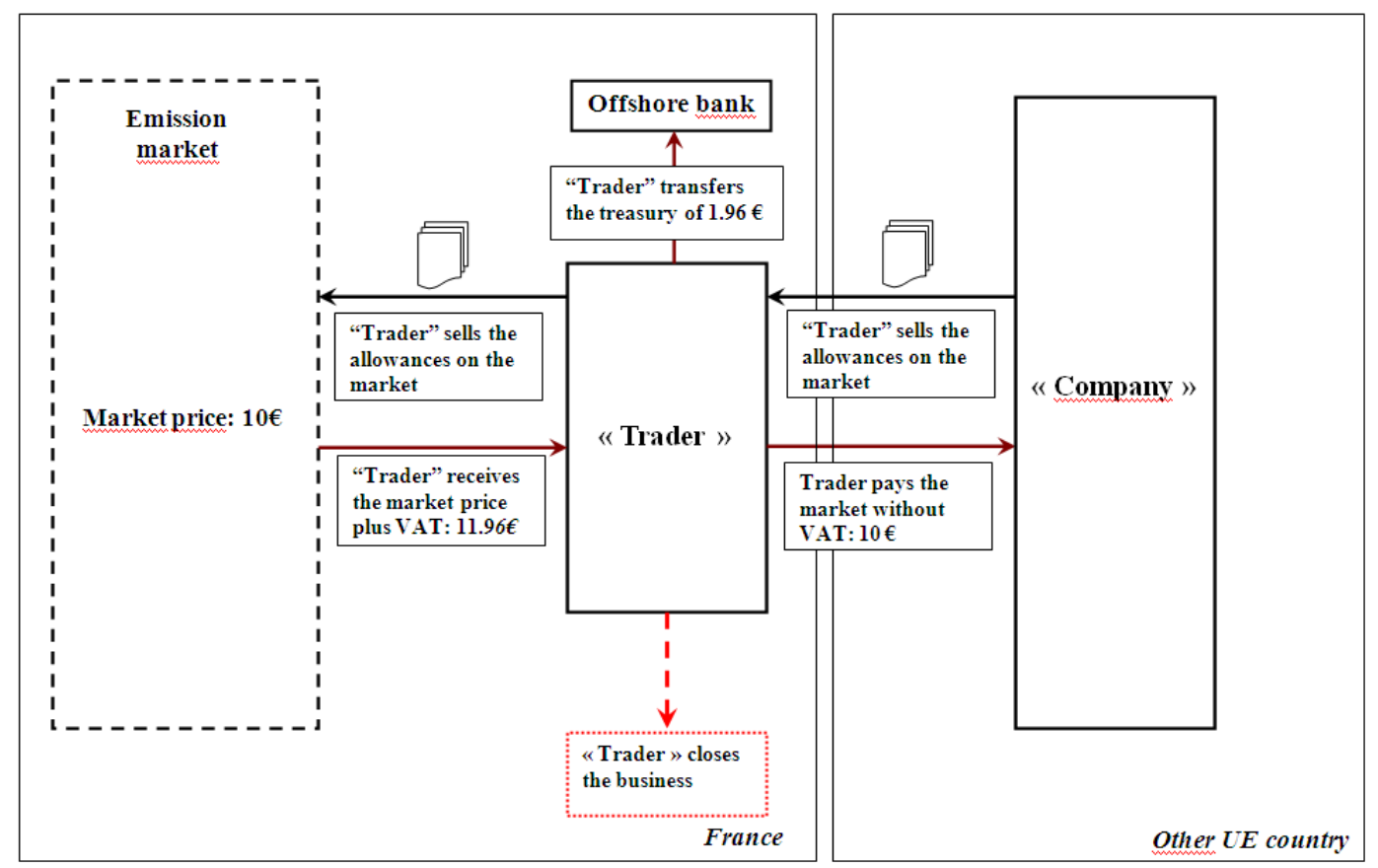

Figure 1: VAT carousel

The trading companies implied in the scheme allegedly imported large volumes of carbon credits VAT-free from other countries then sold the credits on French carbon market BlueNext, having already marked up the price with VAT. The market players purchasing the permits would then have been able to claim the VAT back from the French government. But the suspects allegedly never reported that VAT revenue, pocketing it instead.

The exchange handled a record 19.8 million metric tons of EU carbon permits on June 2 2009 , according to data on Reuters. The previous record was 15.1 million tons on May 28 2009. The exchanged volumes felt nearly to zero following the announce of reverse charge of VAT in the beginning of June 2009.

\section{Forensics methodology}

Our analysis shows that the VAT carousel represented a big part of the exchanged allowances and this massive scheme influenced significantly the market prices. One consequence of the fraud is the unusual high volumes of permits exchanged in the market. In fact in the pick weeks of the carousel the number of transactions was around 10 times higher than normal. After the ban of VAT on carbon trades the volumes dropped and stabilized to a basal regime in the last part months of 2009.

As explained in the Figure 1 the French carbon exchange was exposed to high quantities of selling which should drive the market to significant contraction and to an asymmetric behav- 
ior. We investigate the fundamental level of permits' prices during this period and also the dynamic of the skewness. In a market with a strong selling trend the prices would be pushed to a bearish behavior, thereby showing an excess of negative skewness.

In a previous work Frunza and Guegan [2010] provided a statistical study which identifies the " 'actual"' main fundamentals for $\mathrm{CO}_{2}$ prices through an Arbitrage Price Theory (APT)-like model. We observed that Oil, Dark Spread, Spark Spread and CAC40 explain more than 75 percent of the $\mathrm{CO}_{2}$ prices behavior and the dynamic feature of the dependencies. We use these findings in order to demonstrate that during the VAT carousel the carbon prices ceased to respond to fundamental driving factors but recovered promptly after the VAT ban rule.

\section{Statistical results}

The Figure 2 shows the exchanged volumes of permits on BlueNext market. As expected it picked on June 2 and drooped the day after the VAT ban announce. This finding shows on one hand that a big stake of volumes were linked to the VAT crime and on the other hand that once the carousel suspended the market lacked of fundamental value forcing the "clean" traders to cease shortly the activity. Moreover in February 2009 the prices touched an historical low of 7 euros per ton which is significantly less than the minimal estimated economic price of depolution which is around 10 euros per ton.

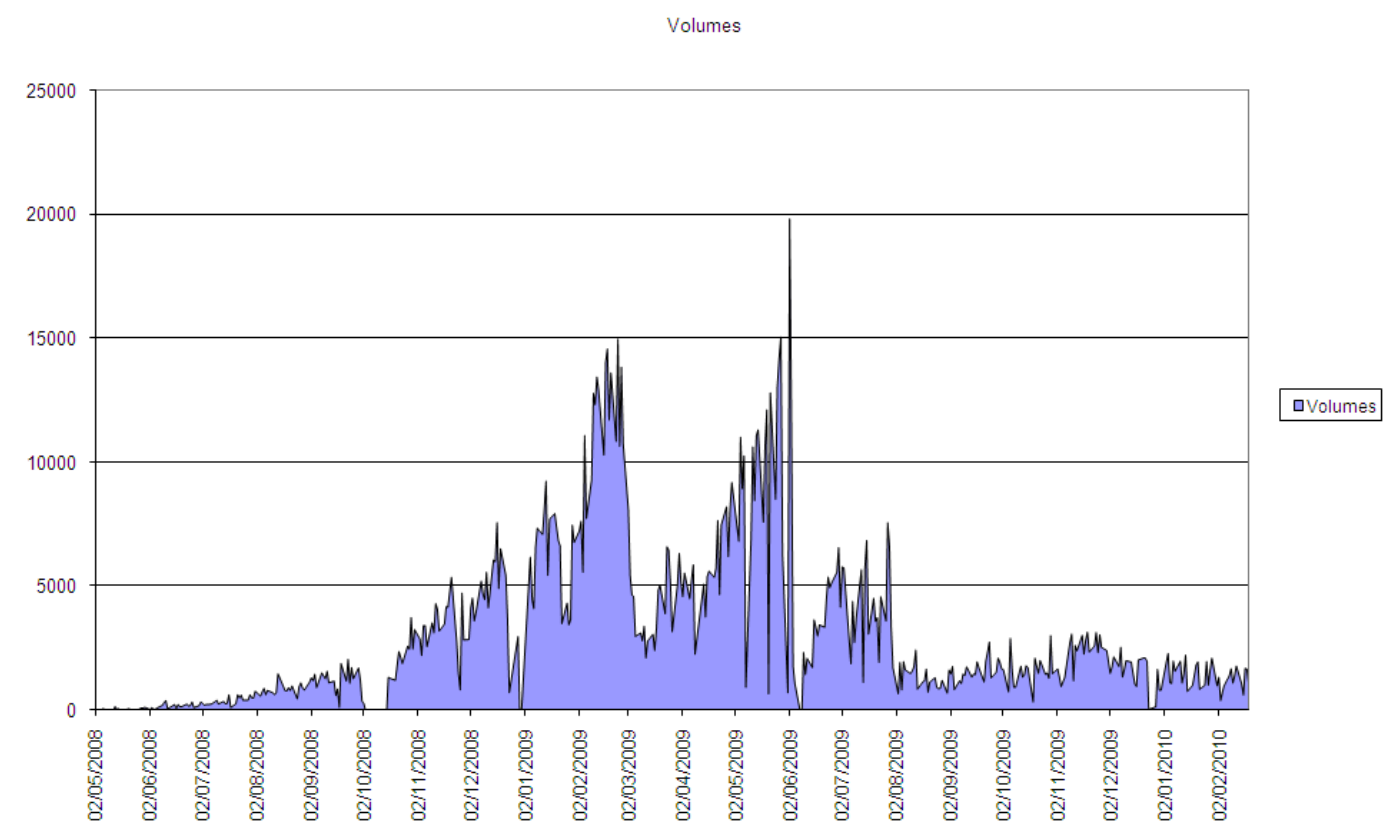

Figure 2: Volumes exchanged on Bluenext

The Figure 3 shows the evolution of the carbon yield skewness measured on a moving window of 90 trading days. We observe that a phenomena of skew reverse appears in the end of 2008 when the VAT carousel allegedly started. As the market become artificially long with large offering the daily yields become predominantly negative. We underline that the VAT fraud 
was an absolute $19.6 \%$ reyturn investement. The return was not linked by any means to market price, thereby pushing the permits to an unusual fundamental level. The skewness reverse to non-negative levels shortly after the end of VAT fraud.

\section{Skewness}

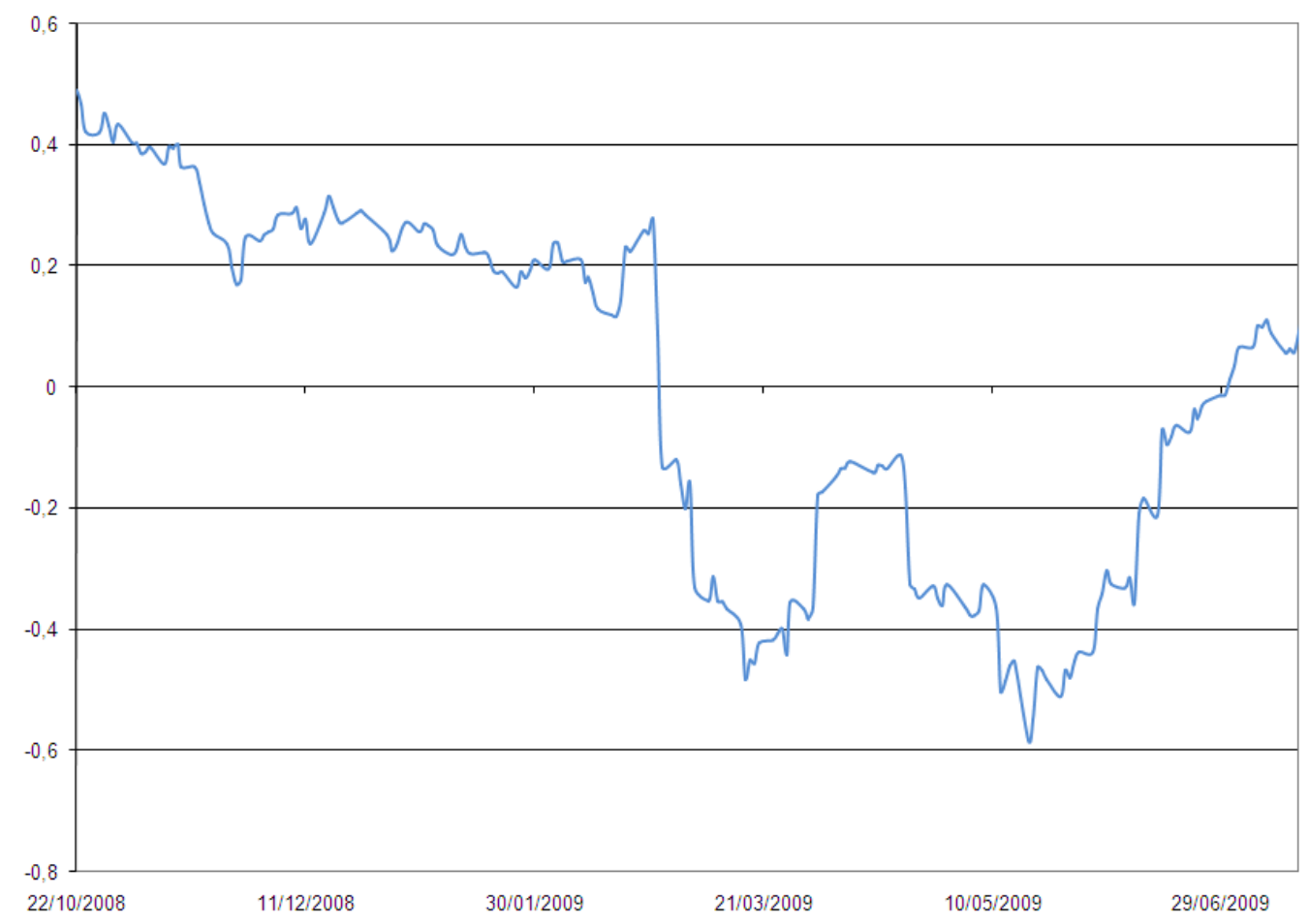

Figure 3: Skewness evolution of carbon yields

Our next argument turns around the fact that in a market strongly influenced by one strategy we would expect significant autocorrelation effect. We investigate the autocorrelation of carbon prices returns on the three period defined in the previous section. The Box-Ljung test reject at $95 \%$ confidence level the null hypothesis on the ante and post period and accept it for the VAT period.

In this section we use the APT model developed by Ross [1976] in order to show the impact of the factors previously identified on the $\mathrm{CO}_{2}$ price evolution, and show calibration results with several noises. We make this calibration using EUA prices on the period 2006 - 2009. Using the historical time series we consider some models based on residuals that go from the classical Brownian diffusion to more sophisticated generalized hyperbolic distributions.

The model has the following representation:

$$
\tilde{r}=\bar{r}+\beta_{1} f_{1}+\beta_{2} f_{2}+\ldots+\beta_{k} f_{k}+\epsilon
$$

where

- $\bar{r}$ : The expected return of Carbon Allowance 

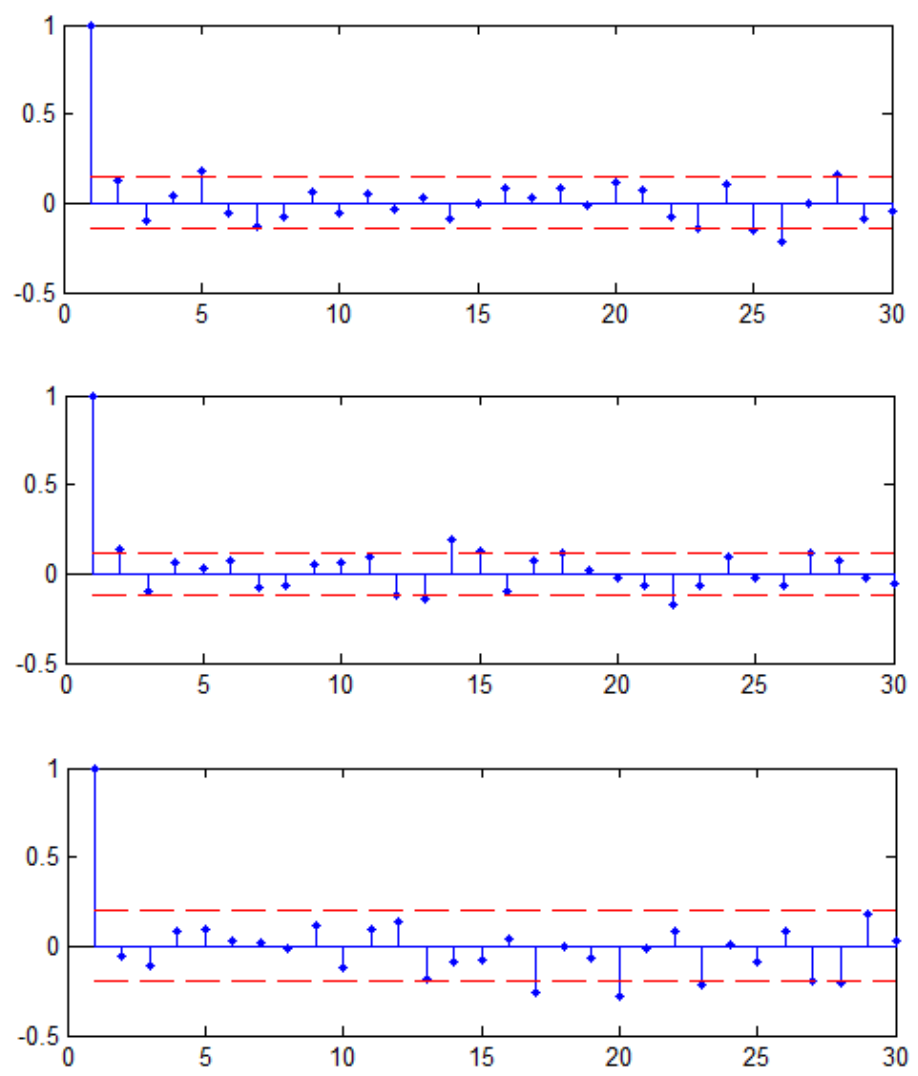

Figure 4: Focus on autocorrelation
Period 1 : ante VAT fraud

Test Box-Ljung : reject the serial correlation

Period 2 : VAT fraud

Test Box-Ljung : accept the serial correlation

Period 3 : post VAT fraud

Test Box-Ljung : reject the serial correlation

- $\beta_{i}$ : The factor loading of factor $i$

- $\epsilon$ : The idosyncratic component

- $\mathbb{E}\left(f_{i}\right)=0 \quad \forall i$

- $\mathbb{E}(\epsilon)=0$

Described by Ross [1976] and based on the underlying hypothesis that the markets are efficient the APT model assumes a Gaussian distribution of the residuals. Given the atypical nature of the $\mathrm{CO}_{2}$, the assumptions of the APT model are in some cases broken. Hence the residuals do not follow a Normal distribution and the dependencies are not stationary over the time. In order to overpass this issue we used different distributions to replace the classic Gaussian modeling for residuals. Amongst the candidate functions t-Student, GED and Normal Inverse Gaussian (NIG) retained our attention for their capacity to take in account heavy tails.

The Table 1 synthesis the results of our static calibration over the considered dataset using a daily timestep, for different residual distributions. The discriminator element is the log likelihood: the higher it is, the best is the modelling. It appears that the level of dependencies of $\mathrm{CO}_{2}$ price are generally close for the different models. But the degree of fitness depends highly of the chosen model. Hence the t-Student distribution for residuals captures 
well the behavior of the residuals and offers a good explanatory ratio for fundamental factors.

The Ljung-Box test of residuals autocorrelation show no presence of persistence at 99 percent of significance for all the distributions.

\begin{tabular}{|c|c|c|c|c|}
\hline & Gaussian & GED & T-Student & NIG \\
\hline Oil & 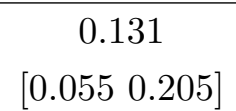 & 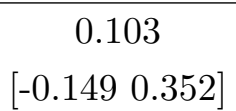 & 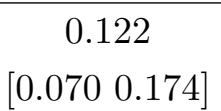 & $\begin{array}{c}0.116 \\
{[0.0630 .169]}\end{array}$ \\
\hline Dark Spread & $\begin{array}{c}0.262 \\
{\left[\begin{array}{ll}0.231 & 0.349\end{array}\right]}\end{array}$ & $\begin{array}{c}0.2115 \\
{\left[\begin{array}{lll}0.014 & 0.468\end{array}\right]}\end{array}$ & $\begin{array}{c}0.261 \\
{\left[\begin{array}{ll}0.221 & 0.304\end{array}\right]}\end{array}$ & $\begin{array}{c}0.260 \\
{\left[\begin{array}{ll}0.221 & 0.302\end{array}\right]}\end{array}$ \\
\hline Spark Spread & $\begin{array}{c}0.002 \\
{\left[\begin{array}{ll}-0.001 & 0.003\end{array}\right]}\end{array}$ & $\begin{array}{c}0.0020 \\
{[-0.0090 .033]}\end{array}$ & $\begin{array}{c}0.002 \\
{\left[\begin{array}{ll}0.000 & 0.004\end{array}\right]}\end{array}$ & $\begin{array}{c}0.002 \\
{\left[\begin{array}{cc}0.001 & 0.004\end{array}\right]}\end{array}$ \\
\hline Equity & $\begin{array}{c}0.12 \\
{\left[\begin{array}{ll}0.017 & 0.242\end{array}\right]}\end{array}$ & $\begin{array}{c}0.157 \\
{[-0.2130 .543]}\end{array}$ & $\begin{array}{c}0.160 \\
{\left[\begin{array}{ll}0.088 & 0.247\end{array}\right]}\end{array}$ & $\begin{array}{c}0.168 \\
{\left[\begin{array}{ll}0.097 & 0.250\end{array}\right]}\end{array}$ \\
\hline$R^{2}$ & 0.24 & 0.24 & 0.23 & 0.24 \\
\hline Log Likelihood & 2054 & 2087 & 2092 & 2094 \\
\hline
\end{tabular}

Table 1: Modelling results

We applied the t-Student based APT model to carbon prices for the period when the VAT carousel took place. Hence we traced the explained dependency (R2) and the model fitting (Likelihood) on a moving window of 90 trading days. The results are presented in Figures 4 and 5 .

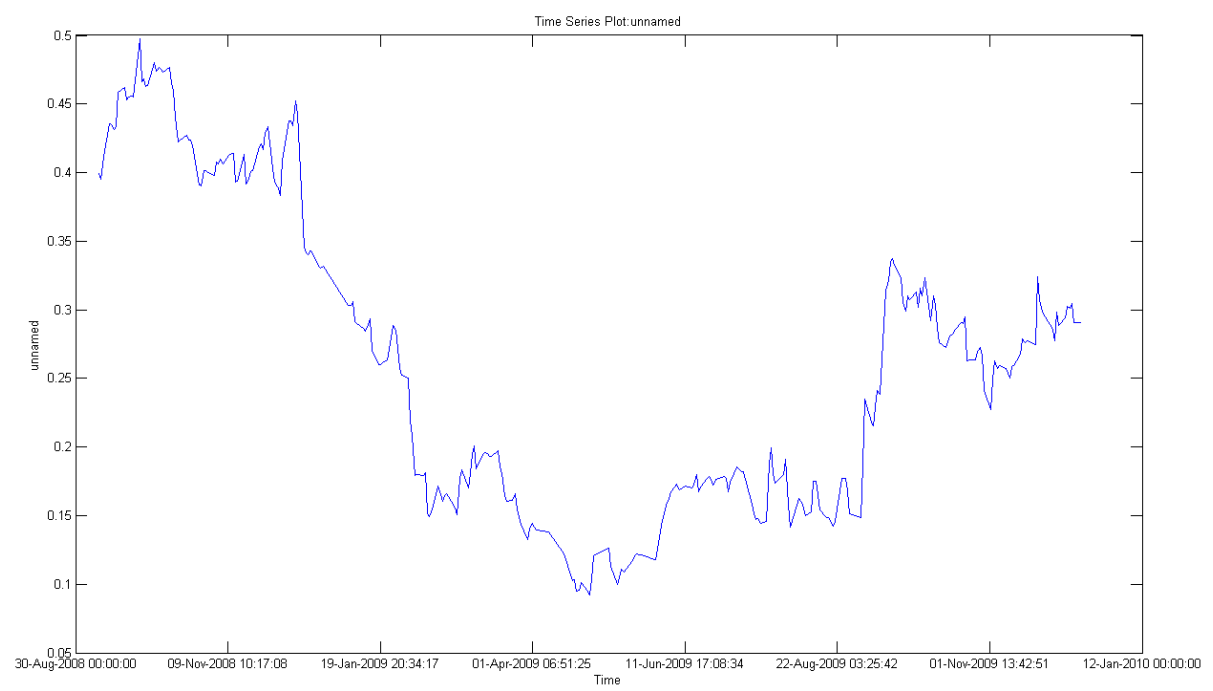

Figure 5: R2 evolution of APT model

The Figure 4 shows the evolution of the explained dependencies during the period when allegedly the fraud occurred. The results indicate that the $\mathrm{R} 2$ decreases significantly in the end of 2008 and regain after the summer of 2009. In fact our APT model quantify to a certain extent the link between the carbon yields and the fundamental factors. If at a certain 
moment the carbon price is linked to some new factor the accuracy of our model diminishes. This situation occurred in our case during the VAT carousel when prices where established mainly by the scheme traders, thereby responding less to fundamentals.

One could justify this downfall in model quality by the global bearish tendency on commodities markets and high volatility that occurred in between end of 2008 and beginning of 2009 . Yet in order to investigate this scenario we focused on the evolution of model likelihood. The likelihood estimates the accuracy of the distribution fit on residuals. The Figure 5 indicates that the likelihood diminished substantially in the end of 2008 with a minim in June 2009 and rallied afterwards. This finding shows that the residual noise of the model became stronger in the same period the VAT carousel was turning as a result of trades that violated fundamental trends.

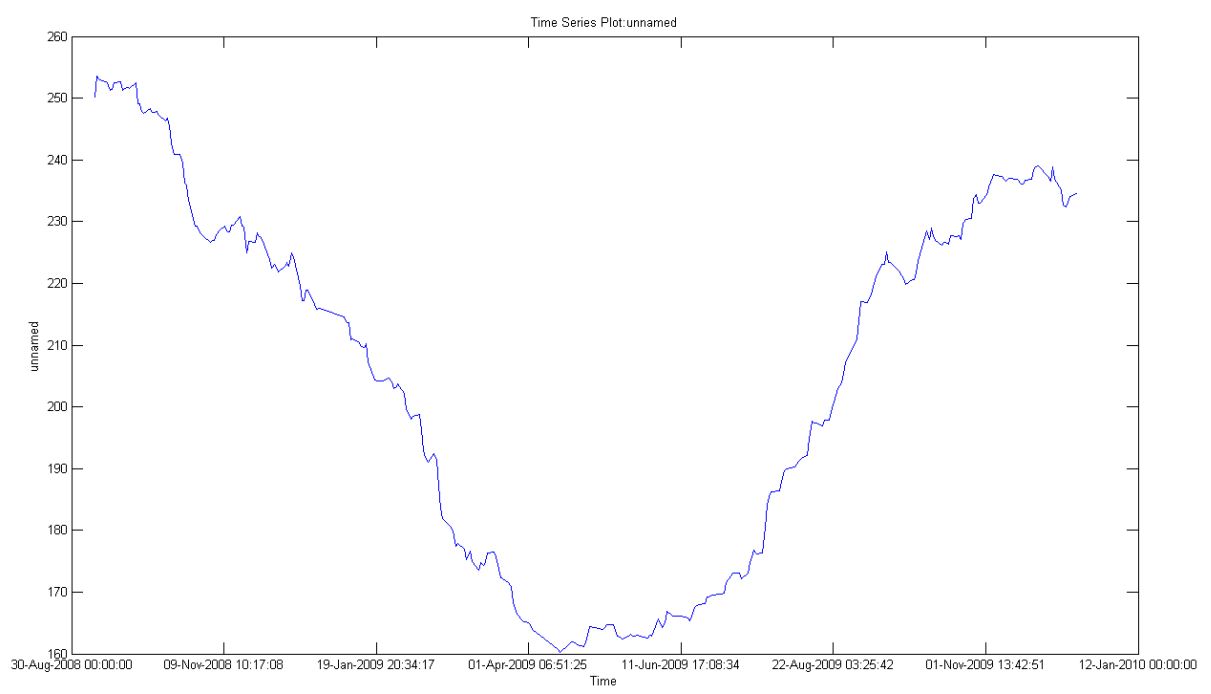

Figure 6: Likelihood evolution of APT model

The previous results underline that a trading "epiphenomena" occurred between August 2008 and June 2009. This "'hidden trading"' modified significantly the behavior of the carbon market, its price level as well as its relationship to other commodities as oil and energy. The epiphenomena was pushed by high trading volumes ceased after the VAT ban on carbon allowances. The link between the hidden trading pattern and the VAT carousel fraud is obvious and the estimated loss for the French government is at least 1.3 billions euros, given our estimations.

\section{Conclusions}

Statistics as forensic instrument is a new field and yet its actual applications are very vast and futures research in this area are justified. The VAT fraud on the carbon permits market that occurred between 2008 and 2009 represented a breach in the regulatory system. Beyond 
the fund pocketing effect the scheme had a strong effect of market manipulation, by drifting carbon prices behavior from its fundamental state. This situation reversed immediately after the French government banned the VAT trade. This type of analysis could be extended to other type of markets and trading system in order to track or search of abnormalities or trading rules violations. 


\section{References}

[1] Artzner P., Delbaen F., Eber J., Heath D., Coherent Measures of Risk, Mathematical Finance, 1999, 3, 203-228

[2] Badescu, A., Kulperger, R. and Lazar, E., (2008). Option Valuation with Normal MixtureGARCH Models. Studies in Nonlinear Dynamics and Econometrics, 12 (2), 15801580 .

[3] Benz E., Truck S., Modeling the price dynamics of $\mathrm{CO}_{2}$ emission allowances, Elsevier Science, 2008

[4] Brandorff-Nielsen, O.E., Processes of normal inverse Gaussian type, Finance and Stochastics, 1998, 2, 41-68

[5] Christoffersen P., Jacobs K. (2002) Which volatility model for option valuation? WP Cirano, Montreal, Canada.

[6] Chorro, C., Guégan, D. and Ielpo, F., (2009). Martingalized Historical approach for Option Pricing, , to appear in Finance Research Letters, 2009.

[7] Daskalakis G., Markellos N., Are the European Carbon markets efficient, Review of Futures Markets, 2008, 17, 2, 103-128

[8] Daskalakis G., Psychoyios D., Markellos R., Modelling $\mathrm{CO}_{2}$ emission allowance prices and derivatives: Evidence from European trading scheme, Journal of Banking and Finance, 2009

[9] Diongue AK, Guegan D., Wolff R.C. (2009), BL-GARCH model with elliptical distributed innovations. . To appear in Journal of Statistical Computation and Simulation, Nov 2009.

[10] Eberlein E., Prause K., The Generalized hyperbolic model: Fiancial derivatives and risk management, Bull. London Math. Soc., 10,1998,300-325

[11] Frunza M.C., Guegan D., An economic view upon carbon emission allowances market, Working paper WP 2009-38, CES Université Paris1 Panthéon-Sorbonne, 2009, ftp://mse.univ-paris1.fr/pub/mse/CES2009/09038.pdf.

[12] Hamilton J.D., A New Approach to the Economic Analysis of Nonstationary Time Series and the Business Cycle, Econometrica, 1989, 57, 2, 357-384

[13] Knittel, C., Roberts M., An empirical examination of restructured electricity prices, Energy Economics, 2005,September, 27, 5, 791-817

[14] Paolella M., Taschini L., An econometriv analyisis of emission Trading allowances, Swiss Finance Institute, 2006, Research “papers, 06-26

[15] Schwartz E.S., The stochastic behavior of commodity prices: Implications for valuation and hedging, The Journal of Finance,1997,52,3,923-973 
[16] Schoutens W., Lévy processes in Finance, Wiley series in Probability and Statistics, 2003.

[17] Uhrig-Homburg M., Michael Wagner, Futures price dynamics of $\mathrm{CO}_{2}$ emission certificates -An empirical analysis, University of Karlsruhe, 2007 